\title{
Evaluation of Severity of Schizophrenia in Tobacco Addicts
}

\author{
Washdev, Zarmeen Qamar, Priyanka, Kheenpal Das, Hina Rajani, Nauman Hashmani, Shah \\ Kamal Hashmi, Raza ur Rehman
}

ABSTRACT

BACKGROUND: Nicotine use is reported more in Schizophrenic patients as compared to general population, which results is decrease efficacy of psychotropic medicines, thus increased severity of illness. OBJECTIVE: The objective of this study is to evaluate the severity of schizophrenia following tobacco use.

METHODOLOGY: This cross-sectional study was conducted at department of Psychiatry Civil Hospital Karachi, Pakistan. Patients were recruited using convenience sampling technique. Clinical symptoms in patients were measured by the 18-item Brief Psychiatric Rating Scale (BPRS), scored 1-7 on each item. RESULTS: Out of the $\mathbf{2 7 6}$ patients included in the study, more than half of the participants were tobacco addicts $(n=150,54 \%)$. The statistical analysis showed significant relation ( $p$ value=0.04) between the Brief Psychiatric Rating Scale (BPRS) and tobacco addiction.

CONCLUSION: This study found that schizophrenia patients with tobacco addiction had worse psychiatric symptoms as compared to those who are not addicted to tobacco.

KEY WORDS: Schizophrenia, Severity, Tobacco Use, Brief Psychiatric Rating Scale (BPRS), Positive symptoms, Negative Symptoms

This article may be cited as: Washdev, Qamar Z, Priyanka, Das K, Rajani H, Hashmani N, et al. Evaluation of Severity of Schizophrenia in Tobacco Addicts. J Liaquat Uni Med Health Sci. 2018;17(01):18-22. doi: 10.22442/jlumhs.181710543

\section{INTRODUCTION}

Schizophrenia is a long-term brain disorder that impairs one's thought process and behavior significantly ${ }^{1}$. According to World Health Organization, it contributes in global burden of diseases within top ten illnesses ${ }^{2}$, affecting approximately 21 million people worldwide ${ }^{3}$. It is observed that patients of schizophrenia consume more nicotine than general population, consequently resulting in long-term poor cognitive performance in comparison to non-smoker patients of schizophrenia ${ }^{4,5}$. Studies have shown different rate of nicotine consumption in schizophrenic patients throughout the world ${ }^{6}$. Morbidity and mortality in schizophrenia patients is significantly affected by chronic tobacco use ${ }^{7}$. Several other studies also stated that smoking individuals with schizophrenia have 2 to 6 times likely age-adjusted mortality from smoking related pulmonary and cardiovascular diseases, as compared to age matched samples ${ }^{7}$. Patients with schizophrenia who smoke tobacco suffer from poor social adjustments compared to nonsmokers $^{8}$. These patients also need higher anti-psychotic doses than non-smokers. Smoking also influences the choice of treatments, studies have reported that patients on clozapine treatment consumed less nicotine on daily basis comparing to those on treatment with typical neuroleptics ${ }^{9}$.

Tobacco in Pakistan is used in different forms such as: Cigarette, Gutka, Sheesha, Niswar etc. To the best of our knowledge; only a few studies have compared the severity of schizophrenia between smoking and non-smoker patients in Pakistan. Therefore, the objective of this study was to evaluate the severity of schizophrenia following tobacco use in patients of a tertiary care hospital in Karachi, Pakistan.

\section{METHODOLOGY}

This study was conducted between January-June 2016 at the psychiatric unit of Civil Hospital Karachi, Pakistan. Two Hundred and seventy-six schizophrenic patients were recruited in the study via convenience sampling. Inclusion criteria were patients who; met ICD-10 (International Classification of Diseases, tenth edition) criteria for schizophrenia, were adults, provided verbal consent, and could understand and communicate in either in Urdu, Sindhi or English language to complete the study scoring ${ }^{10}$. Exclusion criteria included those cases that had an organic mental disorder. Patients selected for the study were approached, for personal interview, by a single interviewer who was qualified in the use of the study scale. A demographic and clinical data questionnaire was completed during this interview. Demographic data collected includes age, gender, occupation, religion, relationship status and tobacco addiction status. Clinical symptoms in patients were measured by the 18-item BPRS, scored 1-7 on each item. 
Questions were asked by primary investigator. BPRS is widely used by clinicians for assessing positive, negative and affective symptoms of individuals who have psychotic disorders, especially schizophrenia ${ }^{15}$. Total and symptom scores on somatic concern, anxiety, emotional withdrawal, conceptual disorganization, guilt feelings, tension, mannerisms and posturing, grandiosity, depressive mood, hospitality, suspiciousness, hallucinatory behavior, motor retardation, uncooperativeness, unusual thought content, blunted effect, excitement and disorientation were calculated. In our study tobacco addicts were defined as those who were unable to consistently abstain, impairment in behavioral control, craving, and have diminished recognition of significant problems with tobacco use.

Statistical Package for Social Studies (SPSS) version 17 was used for analysis. Differences between smoker schizophrenics and non-smoker schizophrenics on BPRS were tested using the independent T-test. Chi square analysis was applied on transformed categorical variables. Significance of BPRS score in genders, mode of treatment and duration of diagnosis of schizophrenia were evaluated by Mann Whitney test. Whereas, BPRS score significance related to duration of treatment and relationship status were tested using Kruskal Wallis test.

\section{RESULTS}

Total patients included in this study were $(n=276)$. The study included approximately twice as many males $(n=180,65 \%)$ with majority $(n=212,76 \%)$ being diagnosed as schizophrenia for more than two years. Most of the patients $(n=225,81.5 \%)$ took medications via the oral route while the rest $(n=51,18 \%)$ took oral plus depot treatment. Marital status showed that more than half of the patients were single $(n=148,53.6 \%)$, one third were divorced $(n=94,34 \%)$ and only a few patients were married $(n=34,12 \%)$. Out of the 276 patients included in the study group, more than half were tobacco addicts $(n=150,54 \%)$, while the rest were non-addicts $(n=126,45.6 \%)$.

Table 2 and 3 shows significant relationship between the BPRS and duration of diagnosis $(p=0.02)$, duration of regular treatment $(p=0.001)$, tobacco addiction $(p=0.04)$ and relationship status $(p=0.01)$. It however shows insignificant association between the BPRS and the mode of treatment $(p=0.82)$.

Schizophrenia patients that were diagnosed for less than 2 years had better mean BPRS score (41.9), compared to those diagnosed for more than 2 years (47.6). Patients taking treatment via oral plus depot route have a better score of 46.8 than those taking it via oral route only with mean score of 48.2 . There is a clear demarcation between the rating score of patients who are non-compliant in taking regular treatment of 60.0. The score tends to get better in patients taking regular treatment for less than 2 months (36.8) than those taking it for more than 2 months (47.8). Similarly, tobacco addicts with a score of 48.6 rank high on the scale as compared to the non-addicts who scored 44.4. Higher score of 54.0 is seen in patients who are married, little less, 49.8 in those who are single and least in divorced patients; 46.9 .

\section{TABLE I:}

DEMOGRAPHICS OF THE PARTICIPANTS

\begin{tabular}{|l|c|c|c|c|}
\hline & $\begin{array}{c}\text { Tobacco } \\
\text { Addiction }\end{array}$ & $\begin{array}{c}\text { Tobacco } \\
\text { Non- } \\
\text { Addiction }\end{array}$ & $\begin{array}{c}\text { OR Ad- } \\
\text { dicts/non- } \\
\text { Addicts* }\end{array}$ & Total \\
\hline Male & 124 & 56 & 2.2 & 180 \\
\hline Female & 26 & 70 & 0.3 & 96 \\
\hline & & & & $\mathbf{2 7 6}$ \\
\hline
\end{tabular}

OR addicts/ non addicts: Odds ratio tobacco addiction/ tobacco non addiction TABLE II: ASSOCIATION OF BPRS TO DISEASE
DURATION, MODE OF TREATMENT AND
DURATION OF TREATMENT

\begin{tabular}{|c|c|c|c|c|}
\hline & & Participants & $\begin{array}{l}\text { Mean } \\
\text { BPRS }\end{array}$ & $\begin{array}{c}\text { P- } \\
\text { Value* }\end{array}$ \\
\hline \multirow{2}{*}{$\begin{array}{l}\text { Disease } \\
\text { duration }\end{array}$} & $>2$ years & 212 & 47.6 & \multirow{2}{*}{0.02} \\
\hline & $<2$ years & 64 & 41.9 & \\
\hline \multirow{2}{*}{$\begin{array}{l}\text { Mode of } \\
\text { treatment }\end{array}$} & Oral & 225 & 48.2 & \multirow{2}{*}{0.82} \\
\hline & Oral +Depot & 51 & 46.8 & \\
\hline \multirow{3}{*}{$\begin{array}{l}\text { Duration of } \\
\text { regular } \\
\text { treatment }\end{array}$} & $>2$ months & 236 & 47.8 & \multirow{2}{*}{0.001} \\
\hline & $<2$ months & 15 & 36.8 & \\
\hline & Non-compliant & 25 & 60.0 & \\
\hline
\end{tabular}

${ }^{*}$ P-Value significant $<0.05$

TABLE III: ASSOCIATION OF BPRS TO TOBACCO ADDICTION AND MARITAL STATUS

\begin{tabular}{|l|l|l|l|l|}
\hline & & Participants & $\begin{array}{l}\text { Mean } \\
\text { BPRS }\end{array}$ & $\begin{array}{c}\text { P- } \\
\text { Value }\end{array}$ \\
\hline \multirow{2}{*}{$\begin{array}{l}\text { Tobacco } \\
\text { Addiction } \\
\text { Status }\end{array}$} & $\begin{array}{l}\text { Tobacco } \\
\text { Addict }\end{array}$ & 150 & 48.6 & \\
\cline { 2 - 4 } & $\begin{array}{l}\text { Tobacco } \\
\text { Non-Addict }\end{array}$ & 126 & 44.4 & \\
\hline \multirow{2}{*}{$\begin{array}{l}\text { Relation- } \\
\text { ship } \\
\text { Status }\end{array}$} & Single & 148 & 49.8 & \multirow{2}{*}{0.01} \\
\cline { 2 - 4 } & Married & 34 & 54.0 & \\
\cline { 2 - 4 } & Divorced & 94 & 46.9 & \\
\hline
\end{tabular}

${ }^{*}$ P-Value significant $<0.05$ 


\section{DISCUSSION}

Many previous studies have found a clear association between schizophrenics and tobacco use ${ }^{11,12}$. Similarly, our study showed that 54 percent of patients were addicted to tobacco; this rate is slightly lower when compared to the western population ${ }^{13}$. This difference probably occurred because of the lower frequency of tobacco use in Pakistan when compared to the developed world ${ }^{13,14}$. Furthermore, the rate of smoking in psychiatric patients is 2.5 times higher than the general population rate for adults residing in United States ${ }^{15}$. The likely reason for this higher rate, as suggested by other studies too ${ }^{16}$. The reason for more tobacco use can be explained by reason that nicotine increases metabolism of antipsychotic and drug is washed out early which decreases the tendency of extra pyramidal side effects. Additionally, a recent study of a population-based sample has shown that people with a mental illness have a higher prevalence of smoking ${ }^{17}$. Hence, this creates room to layout more smoking cessation programs and public health campaigns targeting psychiatric patients to change their smoking habits.

Despite the higher rate of tobacco smoking in schizophrenics, only a few studies have been done to observe its effects on the severity of the disease. Lasser and Kottov in their studies have proven that there is a consistent relationship between the two variables mentioned above, showing an increase in the severity of general psychiatric illnesses and frequent hospitalizations ${ }^{17-19}$. Similar results were observed in our study. On contrary, few studies express that irrespective of smoking status the severity of specific symptoms remained the same ${ }^{20}$. Also, a nationally representative study of mental illnesses in the United States state that non-affective psychotic disorders are not significantly affected by smoking ${ }^{17}$. These differences may occur due to several factors associated with severity of illness like duration of disease onset, co-morbid diagnosis, low $I Q$, socio economic status, education etc.

The incidence of schizophrenia in males and females varies significantly in the literature. A majority of studies reveal that the incidence rates are similar between the two genders. Some studies, though, have found this disease to be more common in males. Our study had the same conclusion where schizophrenia was approximately 2 times more common in males than females. Moreover, some studies illustrate the manifestation of schizophrenia in males at an earlier age than females, explaining why our study had a lack of female population ${ }^{21}$.

Literature review revealed that most of the patients suffering from schizophrenia remained single when the onset of disease is before 25 years of age. The proportion of the patients getting married is far less than the normal population ${ }^{22}$. Problems related to sexual, social and occupational life tends to be some of the reasons identified by the authors for this low marital rate. A lot of studies, in contrast to ours, have however, reported a better effect of marriage on the disease severity showing that spouse play a key role in the support and recovery of the patient ${ }^{23}$.

Patients with psychiatric illness find it more difficult to discontinue smoking habbit ${ }^{24}$, as they are already facing a range of challenges provided by their mental illness. However, it should not be ignored that there is a strong relationship between smoking and decreased life span in a patient with psychiatric illness ${ }^{25}$.

Our study has several limitations that need to be enlightened. First, the study group was not compared with a control group. Second, our data did not include information regarding patients' socio-economic status and education, which could have been one of the reasons for higher tobacco dependency among psychiatric patients. Third, we did not analyze the association between negative symptoms and tobacco dependency and lastly, we were unable to compare different psychiatric illnesses with tobacco smoking, a point that should be considered in future researches.

\section{CONCLUSION}

This study found that schizophrenia patients with tobacco addiction have worse psychiatric symptoms as compared to those who are not addicted to tobacco. We also observed that most of schizophrenia patients were males, single and addicted to tobacco. Therefore, counseling for smoking cessation is important in order to maintain physical as well as psychological health of the patients of schizophrenia.

\section{REFERENCES}

1. U. S. Department of Health and Human Services, National Institutes of Health, National Institute of Mental Health (2017).Schizophrenia (NIH Publication No. 15-3517). Retrieved from https:// www.nimh.nih.gov/health/publications/ schizophrenia-booklet/index.shtml\#pub1.

2. Schizophrenia. April, 2016. World Health 
Organization. Retrieved from: //www.who.int / mediacentre/ factsheets/fs397/en/

3. Keefe RS, Harvey PD. Cognitive impairment in schizophrenia. Handb Exp Pharmacol. 2012; 213: 11-13. doi: 10.1007/978-3-642-25758-2_2

4. Murray C J L, Lopez A D. The Global Burden of Disease, Harvard University Press, Cambridge, MA. USA. 1996. p.21.

5. Thoma P, Daum I. Comorbid substance use disorder in schizophrenia: a selective overview of neurobiological and cognitive underpinnings. Psychiatry Clin Neurosci. 2013 Sep; 67(6):367-83. doi: 10.1111/pcn.12072.

6. De Leon J, Becoña E, Gurpegui M, GonzalezPinto A, Diaz FJ. The association between high nicotine dependence and severe mental illness may be consistent across countries. J Clin Psychiatry. 2002; 63(9):812-6.

7. NIH. Tobacco-Related Mortality and Mental Illness. NIDA. National Institute of Drug Abuse. 04 November, 2013. Available at https:// www.drugabuse.gov/about-nida/noras-blog /2013/ 11/ tobacco-related-mortality-mental-illness.

8. Krishnadas R, Jauhar S, Telfer S, Shivashankar $S$, McCreadie RG. Nicotine dependence and illness severity in schizophrenia. $\mathrm{Br} J$ Psychiatry. 2012; 201(4):306-312.

9. Wijesundera $\mathrm{H}$, Hanwella $\mathrm{R}$, de Silva VA. Antipsychotic medication and tobacco use among outpatients with schizophrenia: a cross-sectional study. Ann Gen Psychiatry. 2014; 13: 7. doi: 10.1186/1744-859X-13-7.

10. Yee A, Mohamed NN, Binti Hashim AH, Loh $\mathrm{HS}$, Singh $\mathrm{MKH}, \mathrm{Ng} \mathrm{CG}$, et al. The Effect of Nicotine Dependence on Psychopathology in Patients with Schizophrenia. Biomed Res Int. 2015; 2015: 730291. doi.10.1155/2015/730291

11. Hamadeh RR, Ansari AA, Jahrami $H$, Offi AA. Cigarette and waterpipe smoking among adult patients with severe and persistent mental illness in Bahrain: a comparison with the National Noncommunicable Diseases Risk Factors Survey. BMC Res Notes. 2016; 9: 77.

12. Mallet J, Le Strat $Y$, Schürhoff $F$, Mazer N, Portalier C, Andrianarisoa M, et al. Cigarette smoking and schizophrenia: a specific clinical and therapeutic profile? Results from the FACESchizophrenia cohort. Prog Neuropsychopharmacol Biol Psychiatry. 2017; Pt B:332-9. doi: 10.1016/j.pnpbp.2017.06.026.
13. Ziedonis DM, George TP. Schizophrenia and nicotine use: report of a pilot smoking cessation program and review of neurobiological and clinical issues. Schizophr Bull. 1997; 23 (2):247-54.

14. Gilani SI, Leon DA. Prevalence and socio demographic determinants of tobacco use among adults in Pakistan: findings of a nationwide survey conducted in 2012. Popul Health Metr. 2013; 11 (1):16.

15. Centers for Disease Control and Prevention (CDC). Cigarette smoking among adults-United States, 1999. MMWR Morb Mortal Wkly Rep. 2001 Oct 12; 50(40):869-73.

16. Dube N. Cigarette Smoking and Schizophrenia. OLR Research Report. 2012 Sep 13; 2012$\mathrm{R}-0402$.

17. Lasser K, Boyd JW, Woolhandler S, Himmelstein DU, McCormick D, Bor DH. Smoking and mental illness: A population-based prevalence study. JAMA. 2000; 284(20):2606-10.

18. Kotov R, Guey LT, Bromet EJ, Shwartz JE. Smoking in schizophrenia: diagnostic specificity, symptom correlates, and illness severity. Schizophr Bull. 2010 Jan; 36(1):173-81.

19. Aguilar MC, Gurpegui M, Diaz FJ, de Leon J. Nicotine dependence and symptoms in schizophrenia: naturalistic study of complex interactions. Br J Psychiatry. 2005 Mar; 186:215-21.

20. Pajk $B$, et al. Effect of tobacco use on symptom severity and medication adherence in Schizophrenia. J Psychiatry. 2015; 18:4.

21. Belli $H$, Ural $C$, Solmaz $M$, Akbudak $M$, Namli $M$, Bayik Y. Association of gender and schizophrenia subtype with age at disease onset in a cohort from rural Turkey. Eur. J. Psychiat. 2012; 26(1):50-54.

22. Lane A, Byrne M, Mulvany $F$, Kinsella A, Waddington JL, Walsh $\mathrm{D}$, et al. Reproductive behaviour in schizophrenia relative to other mental disorders: Evidence for increased fertility in men despite reduced marital rate. Acta Psychiatr Scand. 1995; 91(4):222-8.

23. Ran MS, Wong YI, Yang SY, Ho PSY, Mao WJ, Li $\mathrm{J}$, et al. Marriage and outcomes of people with schizophrenia in rural China: 14-year follow-up study. Schizophr Res. 2017 Apr;182:49-54.

24. Okoli CTC, Wiggins A, Fallin-Bennett A, Rayens MK.A retrospective analysis of the comparative effectiveness of smoking cessation medication among individuals with mental illness in 
Washdev, Zarmeen Qamar, Priyanka, Kheenpal Das, Hina Rajani, Nauman Hashmani, et al.

community-based mental health and addictions treatment settings. J Psychiatr Ment Health Nurs. 2017; 24(8):610-19.
25. Bruce ML, Leaf PJ, Rozal GP, Florio L, Hoff RA. Psychiatric status and 9-year mortality data in the New Haven Epidemiologic Catchment Area Study. Am J Psychiatry. 1994; 151(5):716-21.
AUTHOR AFFILIATION:

Dr. Washdev (Corresponding Author)

Assistant Professor

Department of Psychiatry

Dow international Medical College

Dow University of Health and Sciences

Karachi, Sindh-Pakistan.

Email: devamar88@gmail.com

Dr. Zarmeen Qamar

House officer

Department of Psychiatry

Civil Hospital Karachi, Sindh-Pakistan.

Dr. Priyanka

House officer

Department of Psychiatry

Civil Hospital Karachi, Sindh-Pakistan.

Dr. Kheenpal Das

Medical Officer

Department of Psychiatry

Civil Hospital Karachi, Sindh-Pakistan.

Dr. Hina Rajani

House officer

Department of Psychiatry

Civil Hospital Karachi, Sindh-Pakistan.

Dr. Nauman Hashmani

House officer

Department of Psychiatry

Civil Hospital Karachi, Sindh-Pakistan.

Dr. Shah Kamal Hashmi

Assistant Professor

Department of Public Health

Dow University of Health Sciences

Karachi, Sindh-Pakistan.

Prof. Raza ur Rehman

Department of Psychiatry

Dow University of Health Sciences

Karachi, Sindh-Pakistan. 